
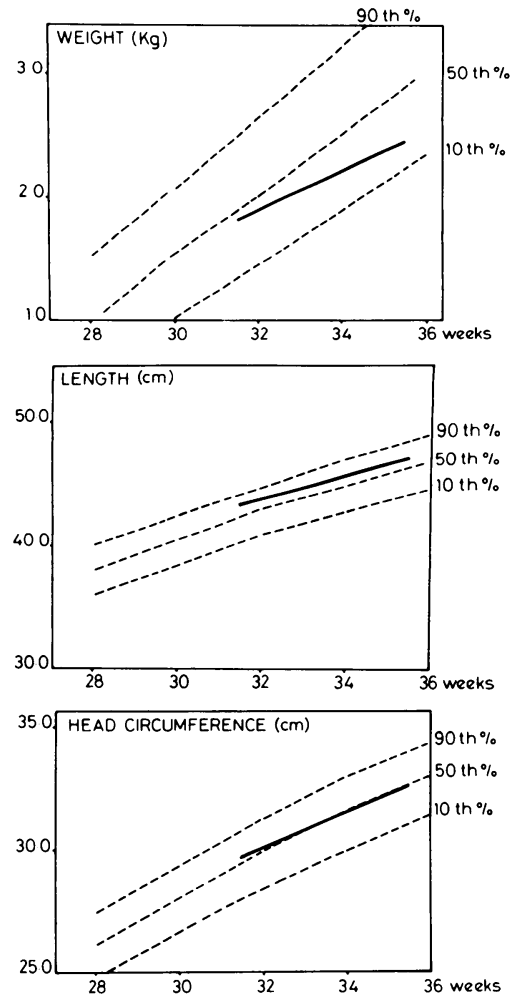

maximum occipitofrontal head circumference with a paper tape measure.

Growth in length and head circumference followed their expected intrauterine curves ${ }^{5}$ far more closely than did weight gain, which was markedly deflected from its expected course. If optimum postnatal growth in preterm infants is that which would have been attained in utero had gestation continued normally, ${ }^{6}$ then these infants might have been diagnosed as failing to grow adequately had weight been the only measure of growth used. However, the much closer approximation of head and linear growth to expected intrauterine patterns suggests that in fact the infants were growing very well. By using these other parameters a far better impression of overall body growth was therefore obtained.

Serial measurements of head circumference and crown-heel length should be used more often in studies of infant growth. These take very little time to perform and, provided care is taken, they are highly reproducible. The uncertainty of optimum milk requirements for low-birth-weight infants might be sooner resolved if these more meaningful measures of growth are evaluated in addition to weight gain.-I am, etc.,

Department of Child Health,

Welsh National School of Medicine,

D. P. Davies 1 Babson, S. G., and Bramhall, J. L., fournal of
Pediatrics, 1969, 74, 890 .
2 Bray, P. F., et al., fournal of Pediatrics, 1969, Bray, P. F., et al., fournal of Pediatrics, 1969,
75,303 .
Winick, M., and Rosso, P., Pediatric Research,

3 Winick, M., and Rosso, P., Pediatric Research,
1969, 3, 181.
4 Davies, D. P., and Holding, R. E., Archives of Disease in Childhood, 1972, 47, 938 .

5 Gairdner, D., and Pearson, J., Archives of Disease in Childhood, 1971, 46, 783.

Usher, R. H., and McLean, F. H., in Scientific Foundations of Paediatrics, ed. by J. A. Davis,
and J. Dobbing. London, Heinemann, 1974.

\section{Misleading Drug Advertising}

SIR, $\rightarrow$ It is a pity that our profession allows itself dual standards. Were Dr. L. F. Prescott's letter' (8 March, p. 572) one of com- ment on a professional colleague's scientific work he would no doubt have extended the courtesy of sending a copy of his letter to that colleague, probably before publication, in case there were a justifiable rebuttal. I am sure Dr. Prescott knows that some of his professional colleagues are employed in the pharmaceutical industry and that to a greater or lesser degree they are involved in what their companies say and how they say it. However, I did not have the opportunity of answering Dr. Prescott's viewpoints privately and must therefore beg space to do so publicly.

Sotacor (sotalol hydrochloride) is a catecholamine antagonist initially developed by the Bristol Group because of its unique pharmacological activity. It is the only drug which blocks all adrenergic beta-receptors and has no membrane-stabilizing activity or intrinsic sympathomimetic activity. ${ }^{1}$ This, we believe, makes it singularly appropriate for the treatment of hypertension. In clinical practice, unlike propranolol, sotalol does not exert a myocardial depressant effect, ${ }^{2}$ which in some patients can precipitate left ventricular failure. Also the absence of intrinsic sympathomimetic activity avoids a paradoxical increase in blood pressure sometimes seen with other beta-adrenergic blocking agents such as oxprenolol. Further points which support the "tailor-made" concept for sotalol include: (1) its exceptionally long half life (approximately 13 hours ${ }^{1}$ ) which permits twice-daily dosage-a desirable feature in the management of hypertension; and (2) its independence of plasma renin levels ${ }^{3}$ - unlike propranolol.

Though many patients with hypertension are asymptomatic, earlier therapeutic regimens have been notorious for iatrogenic symptomatology. Against this background sotalol therapy has been associated with improved well-being. ${ }^{4}$ Sotalol may not be unique in controlling blood pressure during exercise, but the lack of this feature would be undesirable and a statement of its presence is necessary.

Dr. Prescott may not be aware that investigators from many parts of the world convened to review sotalol at a symposium in May 1974. Their contributions, which have been published, provide the endorsement for sotalol from international opinion. -I am, etc.,

Slough

A. J. JOUHAR Medical Director, Bristol Laboratories

1 Shanks, R. G., et al., in Advances in Beta-

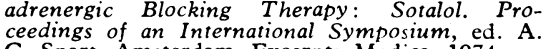
G. Snart. Amsterdam, Excerpta Med.ca, 1974.

2 Dexter, L., et al., ibid.

4 Adachi, T., et al., ibid.

\section{Treatment of Sciatica}

SIR,-A trial, financed by $£ 30000$ from the Department of Health, of manipulation, traction, and exercises in sciatica has recently started at four London hospitals. But it is predictable that no difference will be found between these treatments, which will all give equally poor results.

According to the protocol, patients without gross bone disease or other specified contraindications are admitted to the trial merely on the basis of having pain of sciatic distribution, and they are selected for one or other of the treatments at random. Though the presence of neurological signs is noted, this is not taken into account in allocating patients to treatment groups. Now traction and manipulation constitute the main treatments for reducible disc lesions, whereas neither is of any avail for irreducible displacements. Therefore in cases of sciatica with neurological deficit both manipulation and traction are equally ineffective. ${ }^{1}$ But since the treatment groups will consist of a heterogeneous collection of patients with reducible and irreducible displacements, no valid comparisons can be made between them. In any case the fact that traction is useless in sciatica with neurological signs has been confirmed by Weber. ${ }^{2}$

To be valid a trial of sciatica treated by manipulation or traction should be carried out only on patients without signs of impaired conduction. On the other hand, if neurological signs are present epidural local anaesthesia has been shown to be a successful treatment. ${ }^{3}$

I should therefore like to suggest that, difficult though it may be, the protocol of the trial be changed to give meaningful results.-I am, etc.,

London N.W.3

GABRIEL SYMONDS

1 Cyriax, J., Texthook of Orthopaedic Medicine, vol. 1, 5th edn., pp. 520, 528. London, Bailliere, Tindall, and Cassell, 1969. 2 Weber, H., Journal of the Oslo City Hospital,

3 Goomes, E. W., British Medical fournal, 1961, $1,20$.

\section{Overseas Doctors in the U.K}

SIR,-Dr. T. A. Reddy (1 March, p. 515) may well be right in suggesting that overseas graduates who stay in the U.K. too long become reluctant to retunn home. ${ }^{1}$ I have adduced reasons for believing that two or three years is much too long and that such reluotance becomes established in as little as 18 months. ${ }^{2}$ But we will not help foreign doctors, or ourselves, by persuading the General Medical Council to impose irritating regulations on them. We may fail to persuade such doctons to limit their stay in their own and their home countries' interests, but coercion will make our arguments less persuasive, not more. And-our interpretation of the evidence may even be wrong.-I am, etc.,

Hay on Wye, Hereford

JAMES MATHERS

1 Lancet, 1974, 1, 401. Mathers, J.

\section{Distribution of Hospital Provision}

SIR,-The paper by Mr. M. J. Buxton and Mr. R. E. Klein (8 February, p. 345) was valuable in pointing to the continuing anomalies of resource allocation within the N.H.S. It was unfortunate that only eight regions were able to provide data for the analysis. From profiles kindly provided by area medical officers I have been able to calculate comparable statistics for the five areas in the South-east Thames Region for 1972 (see table). It will be seen that the area health authority (teaching) has a striking disproportion of general medical beds, and of the A.H.A.(T.)s recorded by Mr. Buxton 